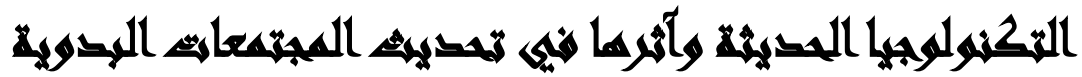

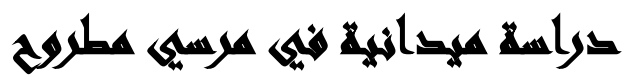

[?]

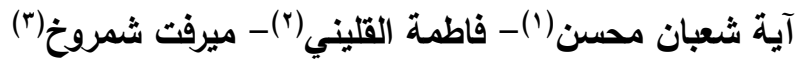

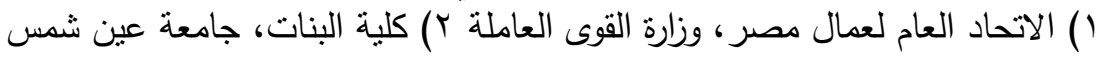

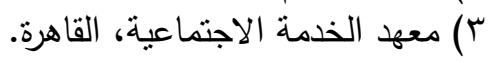

\section{llinaris}

تهدف هذه الدراسة إلى معرفة المتغيرات الناتجة عن استخدام وسائل تكنولوجيا الاتصال

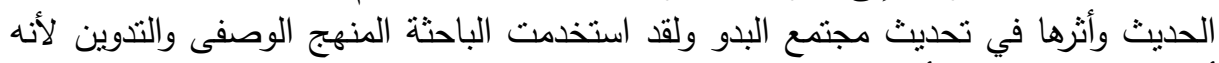

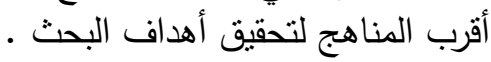

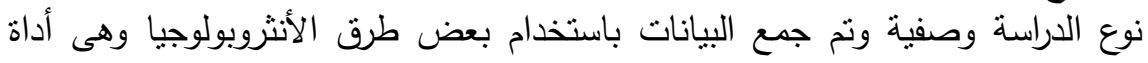

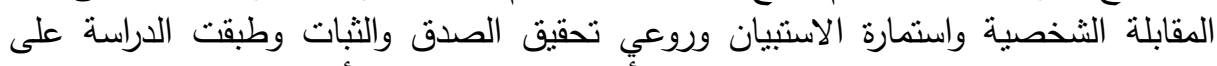

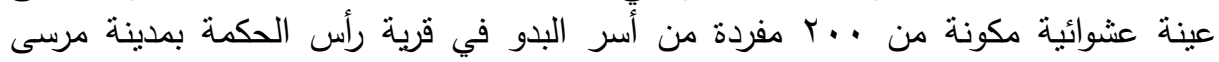

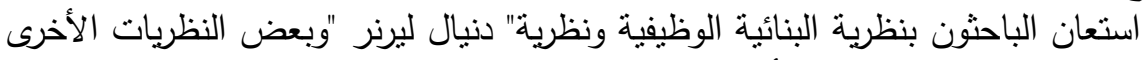
مطروح - معندان

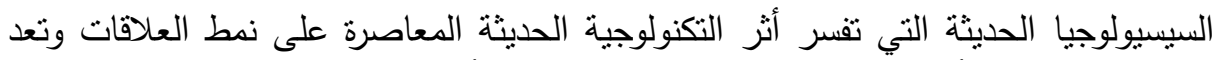

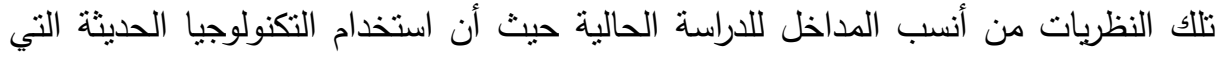

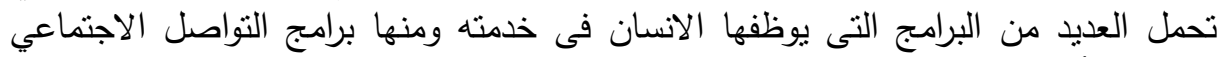

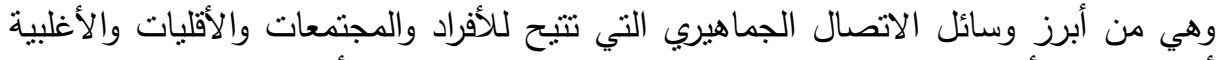

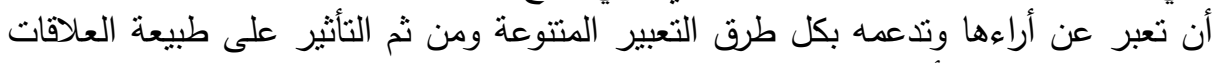

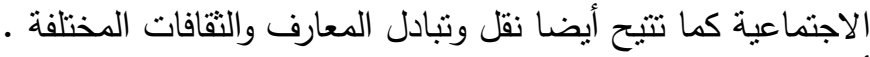

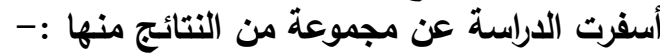

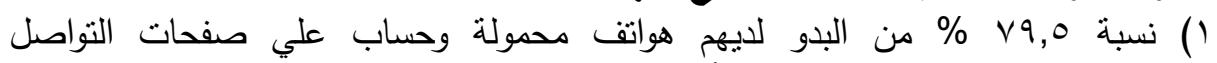
الاجتماعي ويقضون وقتا كبيرا في أستخدم الأنترنت r كما أن أهم التغيرات التي ارتبطت باستخدام التكنولوجيا الحديثة طبيعة العلاقات

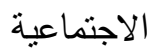
r) ومن أهم المتغيرات الناتجة عن استخدام التكنولوجيا الحديثة إهدار الوقت وضعف

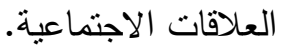


§) كما تشير النتائج إلى وجود V9 \% من حاملي الهواتف ومستخدمي الحاسب الآلي في

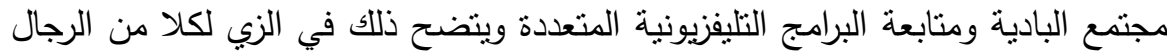

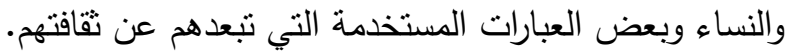

انتهت الاراسة إلى عدد من التوصيات منها:

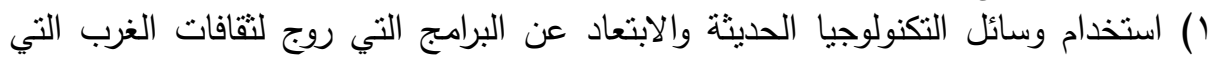
تنتافى مع العادات والتقاليد العربية الثرقية. r) التوعية بأهمية استخدام وسائل التكنولوجيا الحديثة خاصة التهائة مواقع التواصل الاجتماعي والأضرار التي يمكن أن تحدث.

\section{(l)}

أصبحت التكنولوجيا اليوم للمجتمع ذات أهمية كبيرة بعد أن ارتبطت بها كافة فئات المجتمع واعتمدت معظم الخدمات عليها في كل المجالات حتي وصلت التكنولوجيا الي حياتتا بشكل كبير أينما نواجدنا فأصبحنا نستخدمها في كل وقت وفي كل مكان ومن المستحيل الاستغناء عن خدماتها فمثلا في المنزل تستخدم الوسائل التكنولوجية المتعددة منل الراديو والتلفاز وغيرها من الوسائل التي يستقيد منها الانسان ويستمتع بها كذلك الهاتف والسيارة وغيرها، فالهاتف يسهل عمليه التواصل مع الاخرين وإنجاز كثير من الأمور التي قد تتطلب منه وقت وجهد في الذهاب الي المكان لإنجازها، وكذلك السيارة فهي توفر له الوقت والجها عند في تسير أمور حياته وعمله. إن تكنولوجيا الاتصال والمعلومات هي كل ما ترتب على الاندماج بين تكنولوجيا الحاسب الإلكتروني والتكنولوجيا السلكية واللاسلكية والإلكترونيات الدقيقة والوسائط المتعددة من أنثكال جديدة لتكنولوجيا ذات قدرات فائقة على إنتاج المعلومات وجمعها وتخزينها ومعالجتها ونشرها واسترجاعها بأسلوب غير مسبوق بعتمد على النص والصوت والصورة والحركة واللون وغيرها من مؤثرات الاتصال التفاعلي الجماهيري والثخصي معائ معاً. "استخدامات تكنولوجيا الاتصال الحديثة وانعكاساتها على نمط الحياة في المجتمع الريفي -

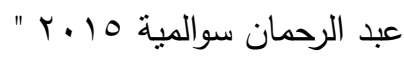

يعيش عالم اليوم في مرحلة انتقال نوعي وسريع، لأنه ينتقل علميا وتاريخيا من قرن إلي

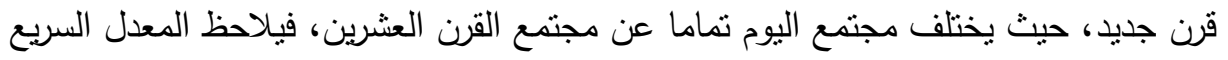


للنطور الصناعي والثورة التكنولوجية والتكتلات الاقتصادية ودخول شبكات التواصل مثل

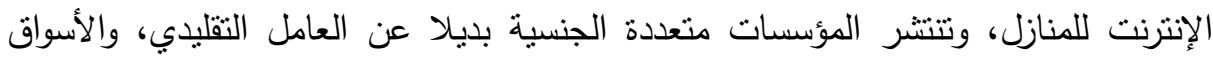
الواحدة (الإككترونية) بديلا عن الأسواق المتعددة (التقليدية)، كل هذا المتغيرات في نمط الحياة

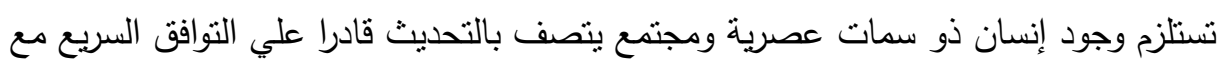
التكنولوجيا والتفاعل والمتغيرات المتلاحقة المحلية والدولية بفاعلية (بثنينة عمارة - . . . ب). كما انتشرت وسائل التكنولوجيا الحديثة في حياة الثباب بقوه واحتلت جزءا كبيرا في حياتتا لما تملكه من إمكانيات واضحة في خلق التواصل الذي يشكل أساس الحياة الاجتماعية للفرد بالرغم من نأثثراته السلبية علي هذه الحياه لهم من جراء إدمان استخدام هذه الوسائل

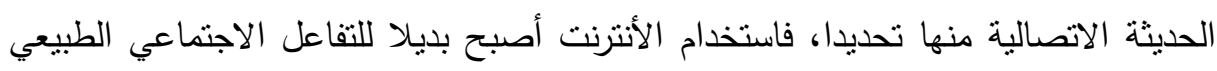

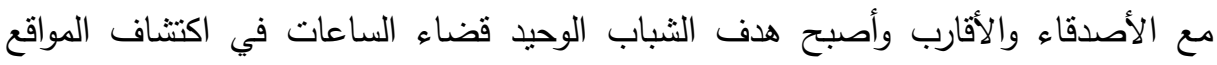
المتعددة مما يعزز الرغبة والميل للوحدة ويقلل من فرص التفاعل الاجتماعي نظرا لتحول هذهاء ولته الوسائل إلي الصديق الجيد المقرب فهي تسد أوقات الفراغ والوحدة عند الثباب خاصة ولثة وأن جزءا كبيرا من هذه الوسائل الحديثة يعتمد علي فكرة بناء عالم افتراضي خاص حيث يقوده ذللك العالم إلي عالم الخيال والثخصيات الوهمية ليصحو من غفوته فيري أنه لا يزال وحيدات فيداء جالسا في مكانه دون تقام وخصوصا في المجتمع البدوي المنعزل عن حياة المدنية الذي لئي يتميز بعاداته وتقاليده الخاصة. لقد دخلت التكنولوجيا حياة الشعوب وبدأت تؤثر علي جميع شُئونها وعادتها وثقافتها وكان لاخول التكنولوجيا الي المجتمعات البدوية دورا كبير في التوعية والتقارب بين سكانها وسكان المدن بكل ما تحمله من إيجابيات وسلبيات وجعل شباب البادية أكثر انفتاحا وتتقيفا

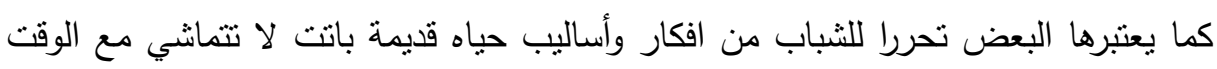
الحالي حيث جعلت من المجتمع البدوي مجتمعا مفتوحا مباح فيه ما كان ممنوعا.

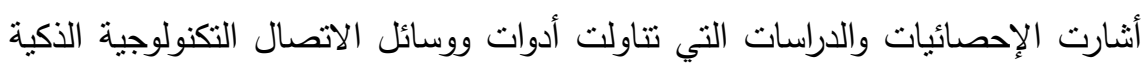
عبر الإنترنت، منل مواقع فيسبوك وتوبتر واليوتيوب والبريد الإلكتروني والتصفح عبر الثبكة

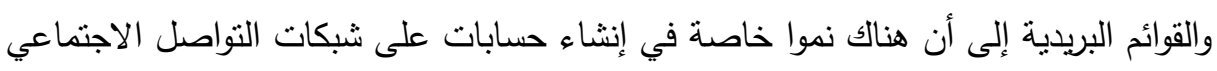

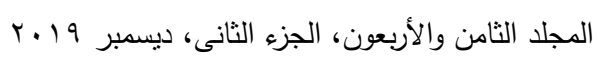


عبر الإنترنت، لاى مختلف الأعمار ومعظمهم من الثباب في مرحلتي التعليم الجامعي وقبل

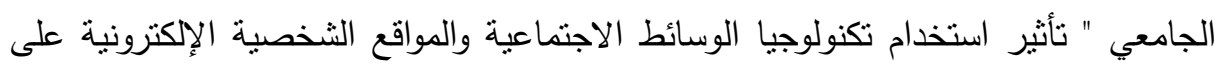

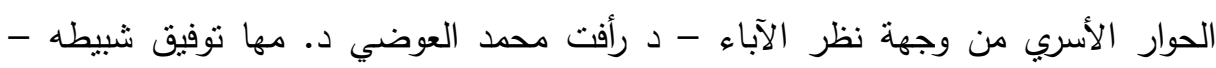

\section{مهيطلة القراسلة}

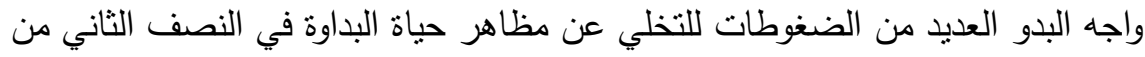

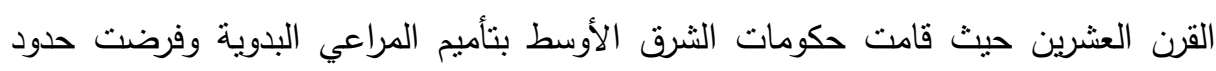

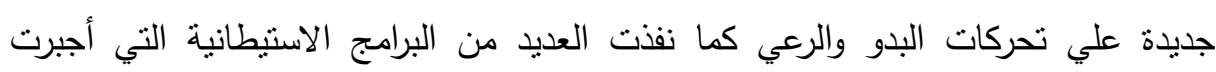

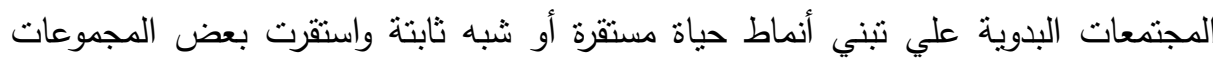

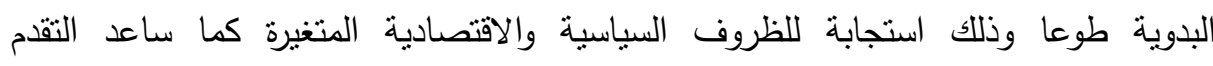
النكنولوجي في تغير حياه البدو من خلال استبدال وسائل النقل التقليدية (الحيوانات)

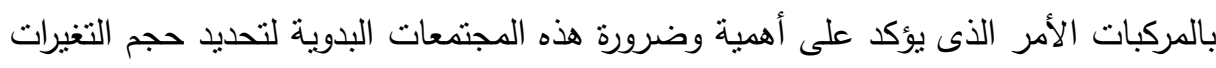

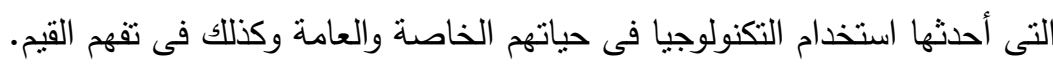

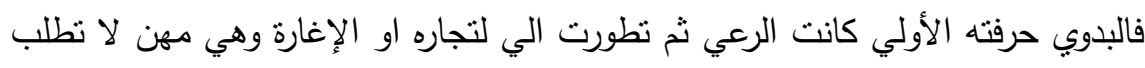

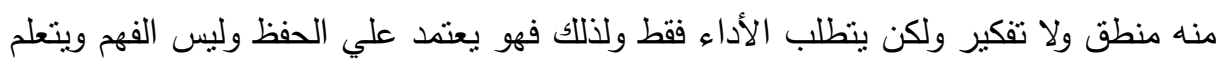

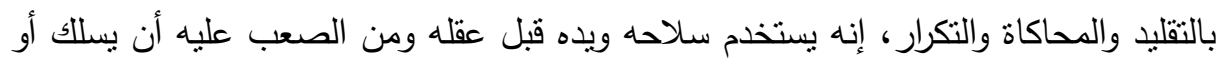

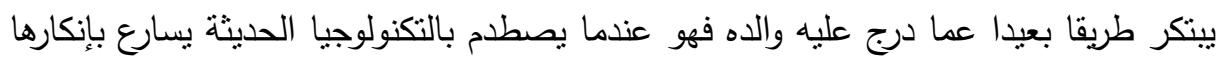

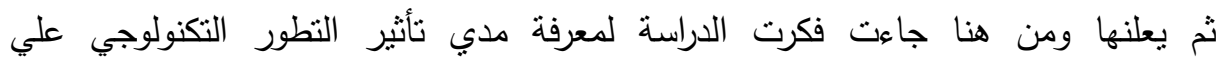
المجتمعات البدوية.

بالرغم من أن المجتمعات البدوية قد شهدت في السنوات الأخيرة تحولا سريعا في كافه

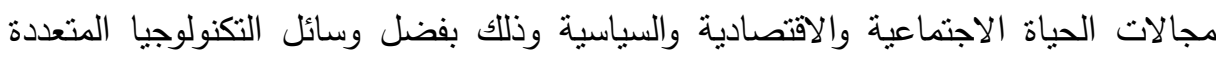

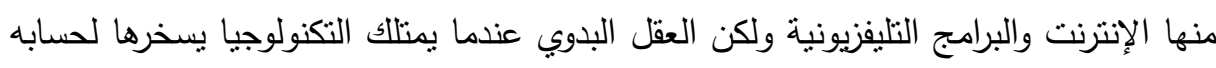

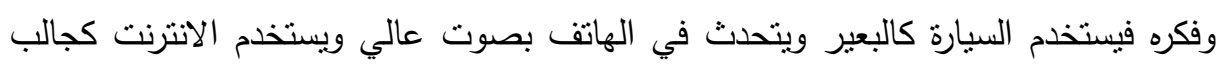


للأفلام (الإباحية) التي لا تليق بأخلاق المجتمع والحاسوب (الكمبيوتر ) كآله كاتبه (فاديه

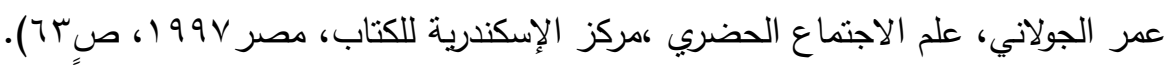
فى دراسة سابقة للباحث عبد الرحمن السوالمة بعنوان " استخدامات تكنولوجيا الاتصال الإليال

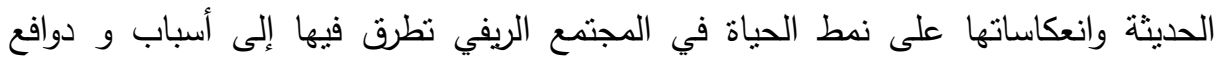

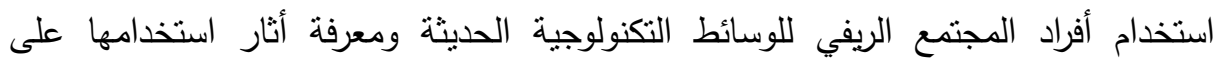

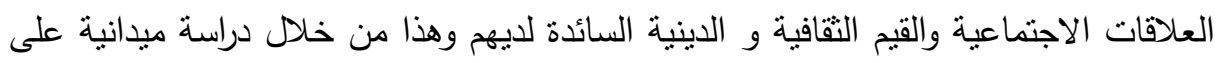

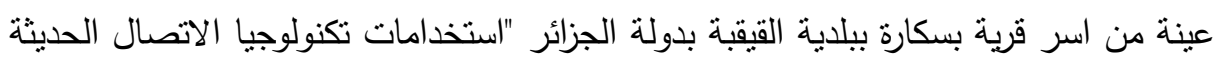

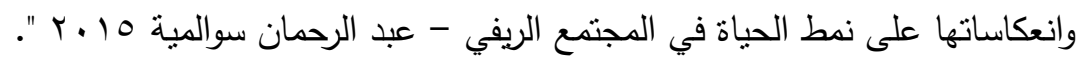

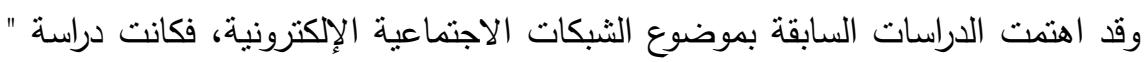

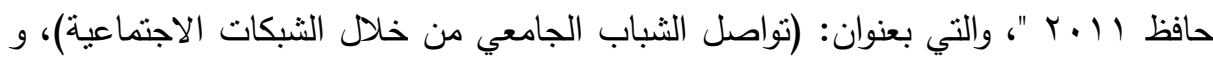

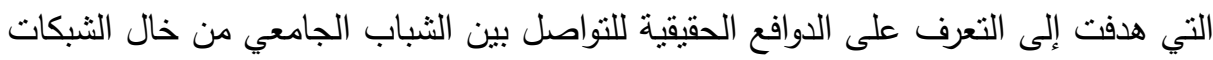

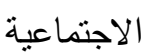

وأثارت نتائج دراسة عبد القوي (9 . ب) والتي هدفت إلى التعرف على دوافع استخدام الثباب اللثبكات الاجتماعية الافتراضية

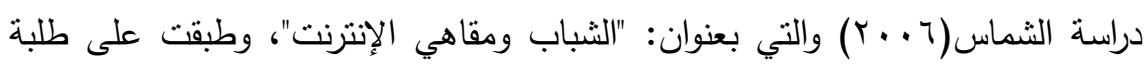

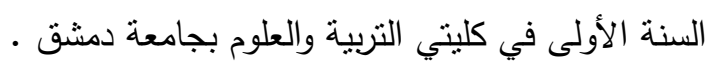

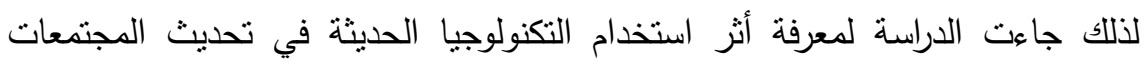

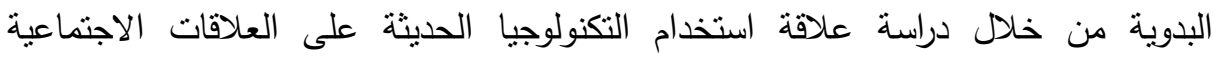

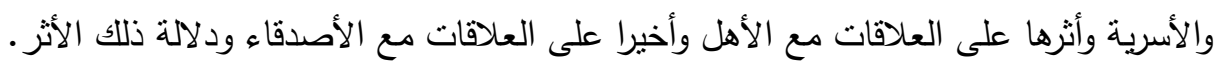




\section{تماولايت التوراسما}

إلى أي ما مدي تأثير التكنولوجيا الحديثة المستخدمة في تحديث مجتمع الدراسة (البناء

الاجتماعي من حيث العلاقات)؟ ملاتيز

\section{أهمية القورسمة}

يعتبر نظور التكنولوجيا ومدي تأثيره علي القيم الخاصة للبدو من أهم المواضيع الجديرة

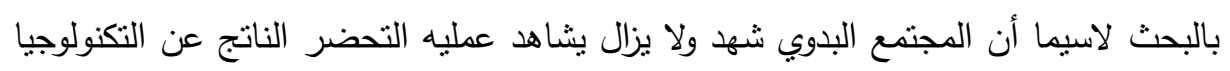

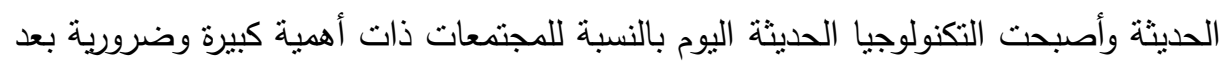
أن ارتبطت بها واعتمدت هذه المجتمعات ع خدمتها في كل المجالات حتي وصلت التكنولوجيا علي حياتنا بشكل كبير وخاصة المجتمع البدوى فى مطروح •

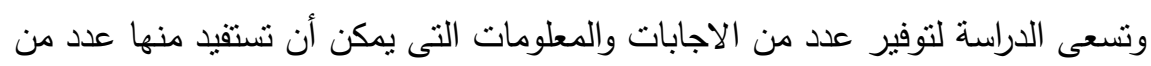

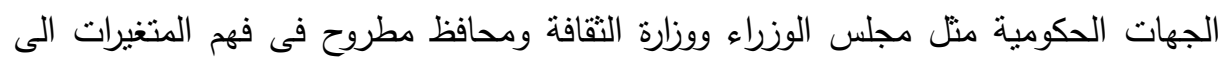
طرأت على المجتمع البدوى عقب استخدام التكنولوجيا الحديثة .

\section{أهساهن الىراسة}

1. التعرف علي كونية آثر استخدام وسائل التكنولوجيا الحديثة في العلاقات الاجتماعية

$$
\text { الأسرية أم تكون في العلاقات الاجتماعية. }
$$

r. التعرف علي كونية أثز استخدام وسائل التكنولوجيا الحديثة في العلاقات الاتئنة الاجتماعية

$$
\text { الأسرية أم تكون في العلاقات الاجتماعية للأصدقاء. }
$$

r. التعرف علي كونية أثز استخدام وسائل التكنولوجيا الحديثة في العلاقات الاجتماعية الأهل

$$
\text { أم تكون في علاقات الاجتماعية للأصدقاء. }
$$




\section{هغرض الفواسم}

ا • يوجد فرق دال إحصائي عند استخدام وسائل التكنولوجيا الحديثة بين متوسط درجات مقياس العلاقات الاجتماعية والأسرية وبين منوسط درجات مقياس العلاقات الاجتماعية

$$
\text { للأهل عند مستوي معنويه (1 +.، • ) لصالح العلاقات الأسرية . }
$$

r. توجد فروق دالة إحصائية بين متوسط درجات مقياس علاقات الأهل ومنوسط درجات

$$
\text { مقياس العلاقات مع الأصدقاء. }
$$

r. يوجد فرق دال إحصائي عند استخدام وسائل التكنولوجيا الحديثة بين متوسط درجات مقياس العلاقات الاجنماعية للأصدقاء عند مستوي معنويه (1 (.،.) لصالح العلاقات

$$
\text { الأسرية معائ. }
$$

\section{همبلحاهي الصراسمة}

مفهوم التكنولوجيا: التعريف الإجرائي وينقسم إلي ثلاث معان: - استثمار المعرفة: تعرف التكنولوجيا بأنها عملية توظيف المعارف لتحقيق حاجات الإنسان

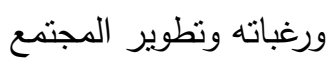

- نتائج استثمار المعرفة: تعرف التكنولوجيا بأنها أنواع الوسائل المختلفة التي تستخدم لتحقيق اللوازم الضرورية لتيسير حياة الإنسان وراحته وضمان بقائه .

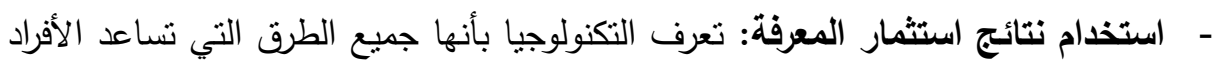
في اكتشافاتهم واختراعاتهم لتحقيق حاجاتهم ورغباتهم (محمد منير حجاب، المعجم

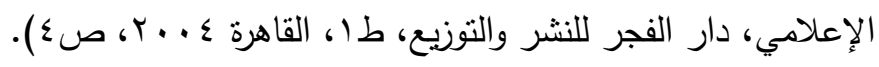

مفهوم التحديث: إجرائيا: يرتبط مفهوم التحديث بالتتمية والتغير والتقدم، فإما أن يكون تطورا تكنولوجيا أو اجتماعيا أو نفسيا فيعني التغير في اتجاهات الأفراد وسلوكهم الاجنماعي بوني

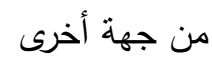


التغير: هو المفهوم الأكثر موضوعية ويككن تناوله بأي اتجاه أو أي شكل، أي أن التغير في

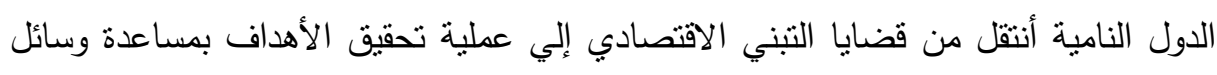

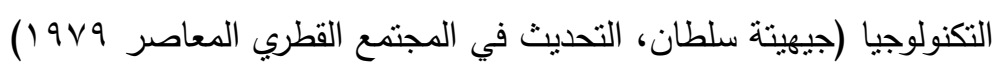

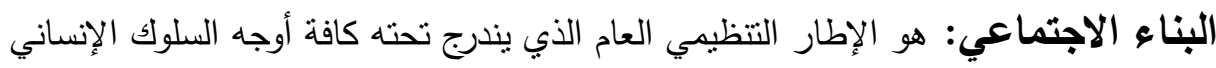

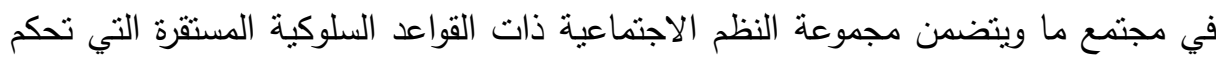

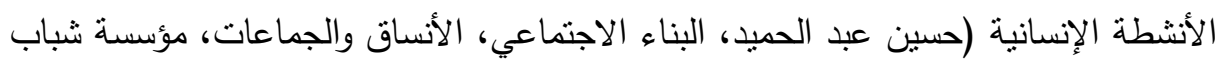

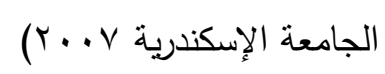

العلاقات الاجتماعيةة: تعرف بأنها السلوك الذي يصدر عن مجموعة من الناس إلي المدي

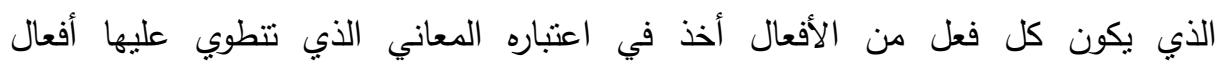

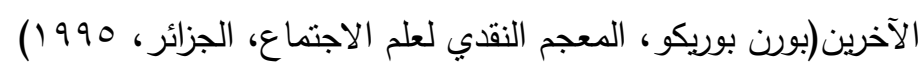

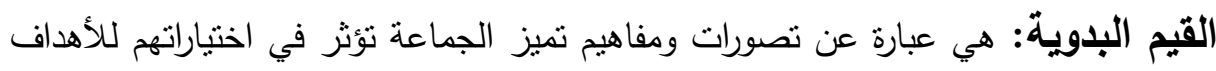

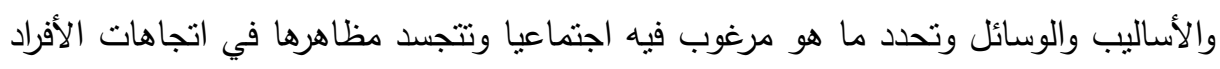

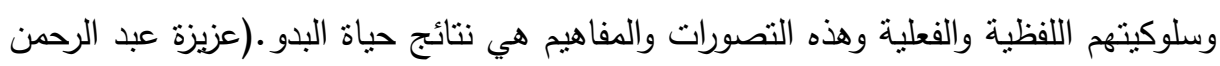

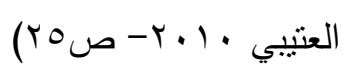

مفهوم البداوة وخصائصها: تعرف البداوة بأنها أنماط الحياة المجتمعية التي تسود بوجه البها

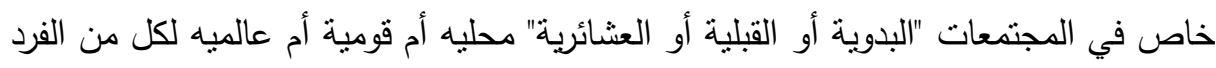

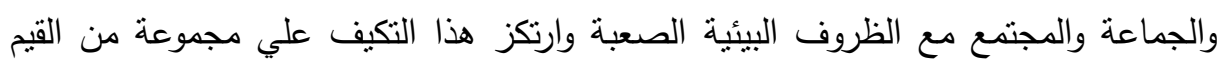

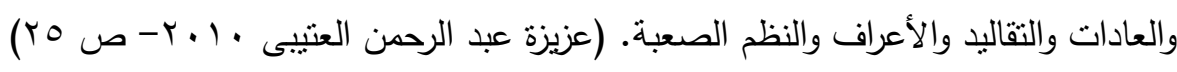

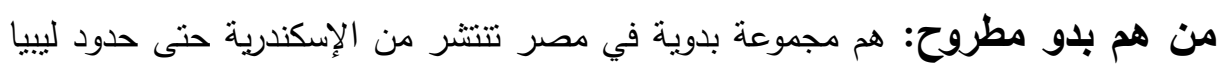

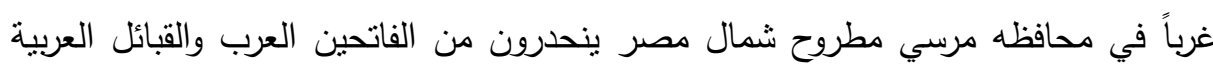

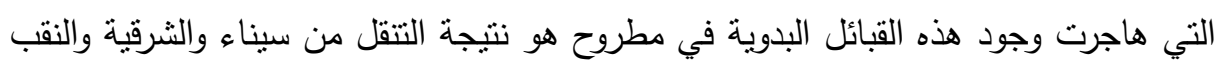

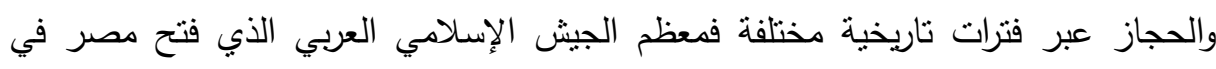

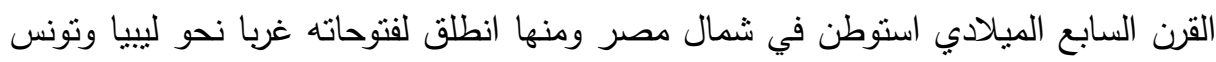
والمغرب. 


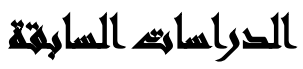

- دراسة حنان الشهري: بعنوان "أثر استخدام شبكات التواصل الإكترونية على العلاقات الاجتماعية “لفيس بوك وتويتر نموذجا" حيث هدفت هذه الدراسة إلى التعرف على بلى الأسباب التي تدفع إلى الاثتراك في موقعي الفيس بوك وتويتر والتعرف على طبن طبيعة

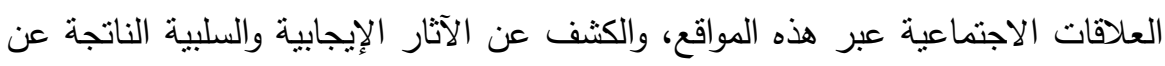

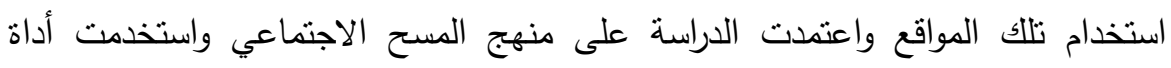

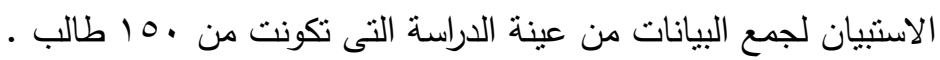

وتوصلت الدراسة لعدد من النتائج أهمهما : الهن

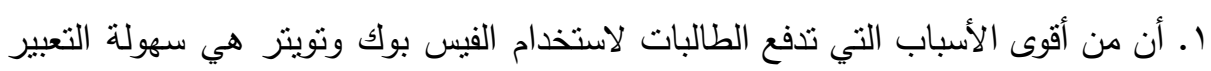
عن آرائهن واتجاهاتهن الفكرية التي لا يسنطعن التعبير عنها صراحة التهاب في المجنمع.

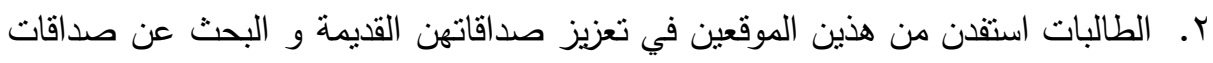
جديدة والتواصل مع أقربائهن البعيدين مكانياً .

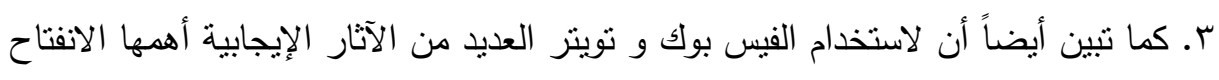
الفكري والتبادل الثقافي فيما جاء قلة التفاعل الأسري أحد أهم الآثار السلبية

ووضعت الاراسة مجموعة من التوصيات منها : ا ـ تتظيم دورات لتوعية الفتيات على حسن استخدام مواقع التواصل الاجتماعي .

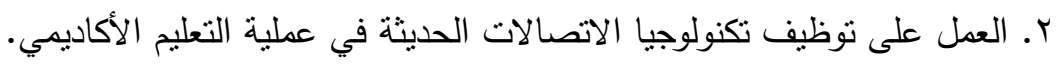

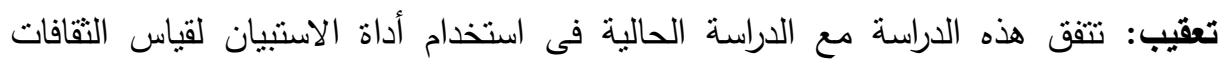
المختلفة من خلال استخدام التكنولوجيا الحديثة، كما تتفق أيضا فى النتائج أن استخدام وسائل

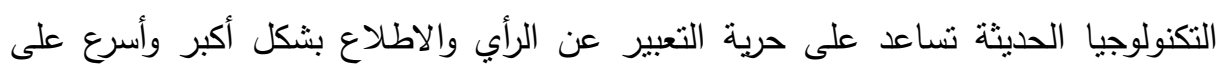

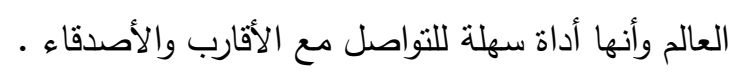

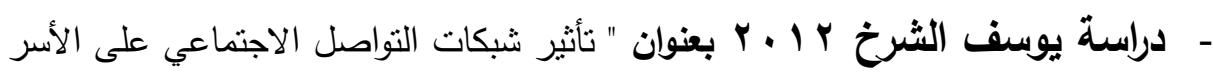

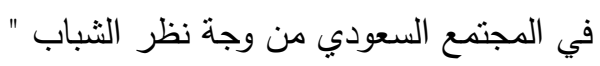


هدفت الدراسة إلى معرفة تأثثر شبكات التواصل الاجتماعي على الثباب وأسرهم وعاداتهم

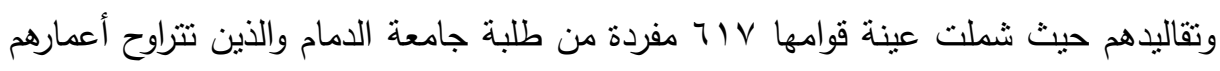

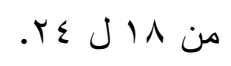
وأظهرت الدراسة مجموعة من النتائج 1. هنالك تأثير على علاقة الثباب مع اسرهم جراء استخدام تلك الثبكات.

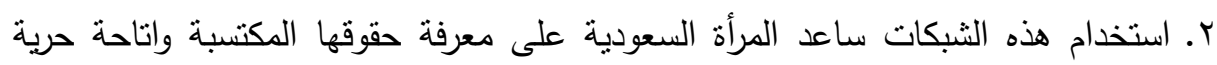
الكلام لها. r. هناك احتمالية حدوث تغير اجتماعي فى بنية المجتمع السعودي.

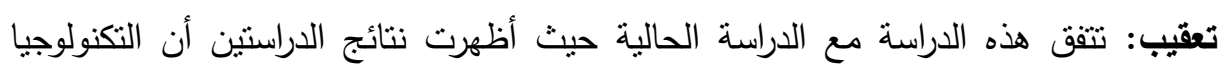

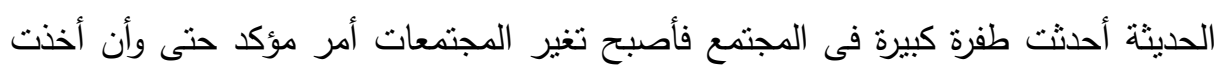

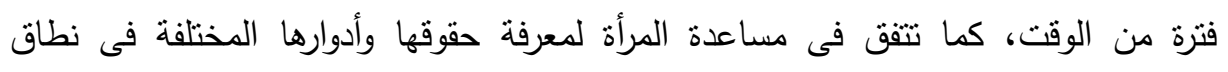
مجتمعها واكتساب ثقافات وخبرات تعلم حرف ومهن مختلفة . - دراسة محمد خليفي r r . ب بعنوان "تأثنير الإنترنت على المجتمع" وهدفت الدراسة إلى التعرف على نأثثر الانترنت فى المجتمع من خلال نقض فوائد شبكة الانترنت

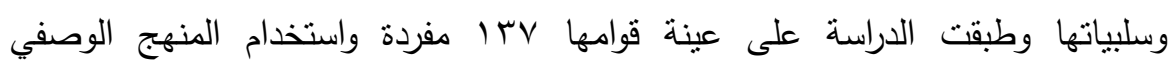
التحليلي. توصلت لنتائج: ا. أن هناك تعدد لأسباب الاستخدام وفي مقدمتها أغراض الاتصال، وتبادل المعلومات مع الآخرين r. ان شبكة الإنترنت تعد آداه للغزو الثقافي، وتنبب مشاكل اجتماعية وأخلاقية، وصحية بكثرة استخدامها.

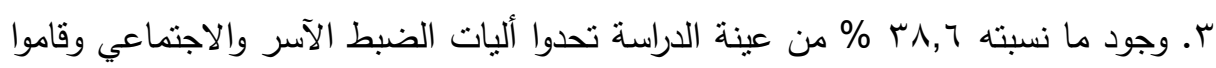
بلقاءات وجه لوجه للتعارف 
تعقيب: تتفق هذه الدراسة مع الدراسة الحالية فى استخدام منهج الوصفي التحليلى وأدوات المقابلة والاستبيان بالإضافة إلى أن معظم عينة البحث لديهم الرغبة فى استخدام الإنترنت،

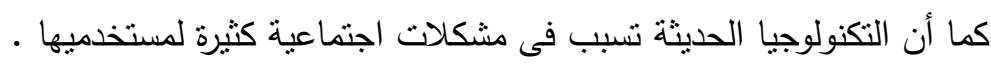
- دراسة علاء الخواجة ه . . ب بعنوان " تأثثر الإنترنت على الثباب فى مصر والعالم

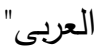

هدفت الدراسة إلى التعرف على مدى استخدام وانتشار الإنترنت فى مصر والعالم العربى

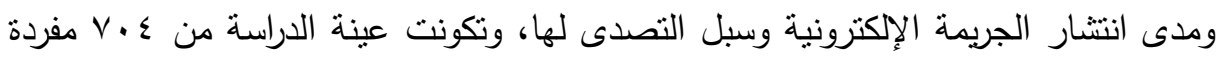
من الثباب. وانتهت الدراسة لعدد من النتائج ا ـ تركيز الثباب على الجانب الترفيهي فى استخدام الانترنت

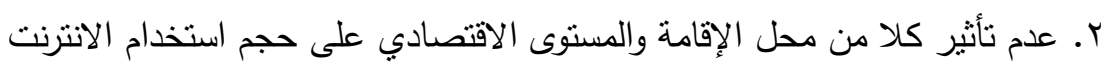

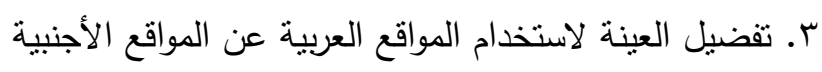
ع. اختلاف وجهات نظر الثباب عن أولياء الأمور حول تحديد إيجابيات وسلبيات الإنترنت

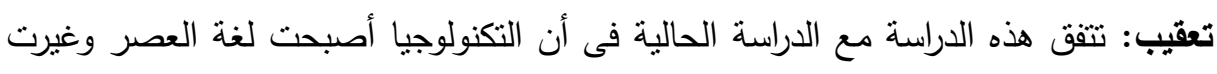
فى ثقافات الأجيال القادمة، كما تتقق فى أن عدد كبير من شرائح المجتمع المختلفة تستخدم

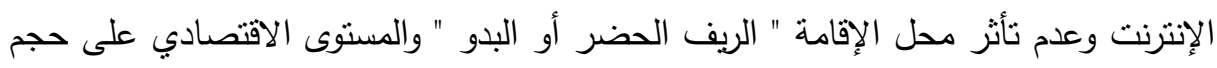

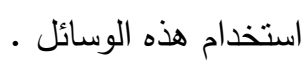

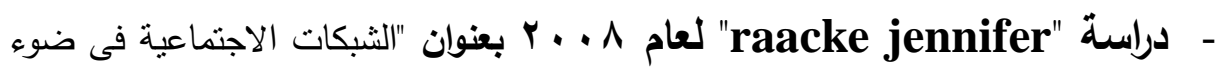
نظرية الاستخدامات والاشباعات" أكدت الدراسة أن الأغلبية العظمى من المستخدمين لمواقع فيس بوك يستخدمونه من

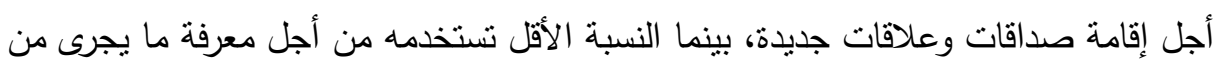

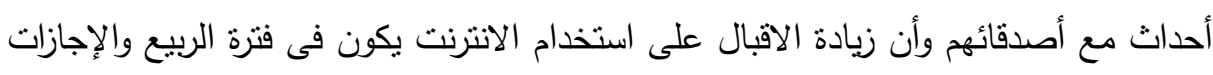
كما يقضى المستخدمين متوسط ثلاث ساعات يوميا أمام صفحاتهم لإقامة علاقات اجتماعية 
تعقيب: تتفق هذه الدراسة مع الدراسة الحالية فى استخدام وسائل التكنولوجيا الحديثة فى تكوين

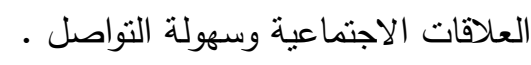

- دراسة عبد الرحمن السوالمة 10 ب ب بعنوان "استخدامات تكنولوجيا الاتصال

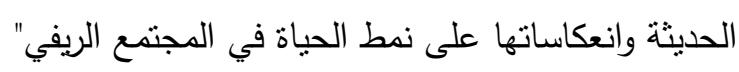

هدفت الدراسة لمعرفة أسباب ودوافع استخدام أفراد المجتمع الريفي للوسائط التكنولوجية الرئية الحديثة وكذا معرفة أثار استخدامها على العلاقات الاجتماعية والقيم النقافية والدينية السائدة لديهم وتحليل التغيرات التي عرفها المجتمع الريفي، جراء التحديث واحتكاكه بالوسائط التكنولوجية الحديثة . توصلت الاراسة لنتائج منها: - غالبية الأسر تمتلك للهوائيات "الهواتق المحمولة" وذلك بنسبة . . 1 \% \% - الدافع الأول في استخدام أفراد المجتمع الريفي للهاتق المحمول هو الاتصال بالأصدقاء والأسرة لمعرفة أحوالهم وأخبارهم وتقديم التهاني والتعازي في أوقات المنات المناسبات.

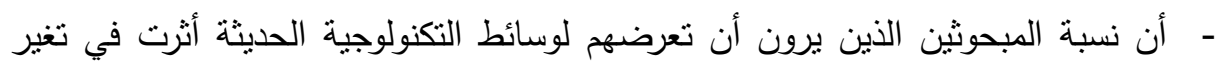

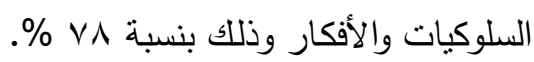
تعقيب: تتفق هذه الدراسة مع الدراسة الحالية فى التكنولوجيا الحديثة أثرت بنسبة كبيرة فى والى تغير سلوكيات وأفكار المستخدمين.

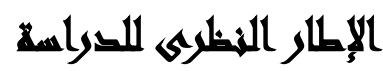

البدو هو لفظ أطلق على أهل الصحراء، لأن طبيعة حياتهم يغلب عليها التتقل من

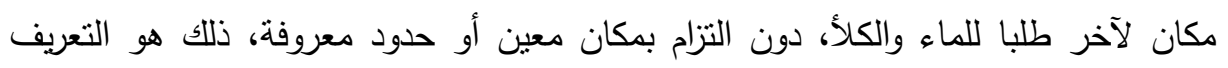

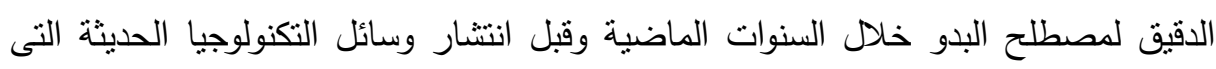
غيرت الكثير من سمات البدو خلال الآونة الأخيرة وأصبحت حياتهم لا تميل إلى التتقل من مكان إلى أخر مثلما كان يحدث فى الماضي فى الصحراء وأصبح البدو اليوم أكثر استقرارا فى مكان واحد. 
فالبدو اليوم أصبحت لهم منازل بدلا من الخيام التى كانت تستخدم للمعيشة من قبل

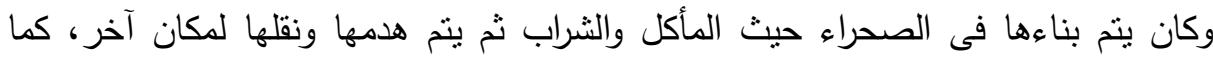
تغيرت وسائل النقل بالنسبة للبدو من الجمال والحمير والبغال لوسائل أكثر حداثة منل السيارات والدراجات البخارية إلى غير ذلك.

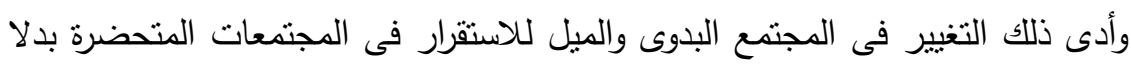

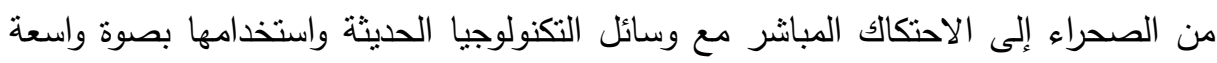

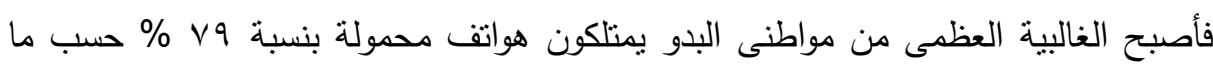

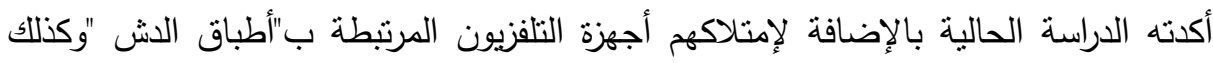
الأمر بالنسبة لأجهزة الكمبيوتز ووصلات الإنترنت. ومع امتلاك كل هذه الوسائل الحديثة " الهواتف المحمولة وأجهزة الكمبيوتر والتلفزيون " واستخدام البدو لها بكثرة، نتج عن ذلك حدوث تغيير جذرى فى هذه المجتمعات وطباعها

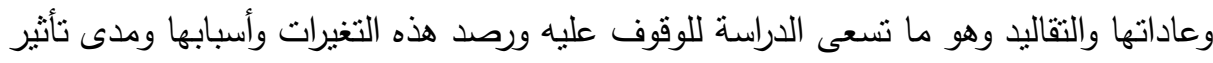
هذه التغيرات على المجتمعات البدوية سواء فى طريقة التفكير أو تغيير عدد من العادات

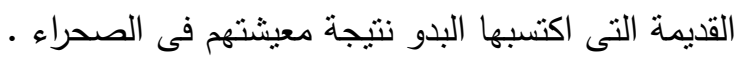

\section{إجبراءايت التراسة}

المنهج هو إطار عام أو إسلاب رئيسي يستهدف تحقيق أهداف استراتيجية مرتبطة

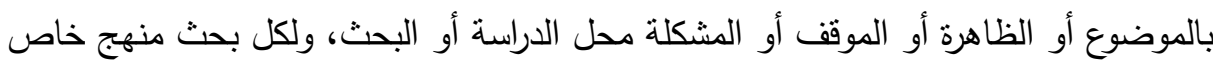
به يسير على نهجه " Thomas hrgoy1996" وتعتمد هذه الدراسة على منهج : المنهج الوصفي التحليلي: يعتمد علي التحليلات الكمية وهو يهدف الي اكتشاف الوقائع ووصف الظواهر وصفا دقيقا وتحديدا خصائصها تحديدا كما وكيفا وهي تقوم بالكثف عن

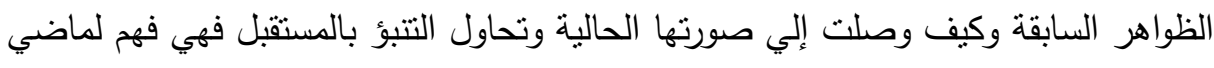
الظاهرة وحاضرها وكذلك مستقبلها ولإسقاط هذا المنهج علي دراستتا يمكننا القول أن بحثنا 
ينقسم إلي قسمين أولهما دراسة وصفية وثانيها دراسة تحليلية للظاهرة.(طلعت السروجي

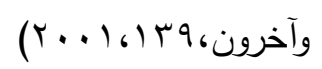

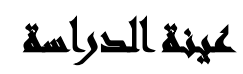

تكونت العينة من (·. (Y) مفرده تم اختيارها بطريقه عشوائية من قرية رأس الحكمة بمدينة مرسي مطروح.

\section{أسوامت التواسمة}

استمارة الاستبيان: وهي من أهم التقنيات وأكثرها شيوعا في العلوم الاجتماعية التي

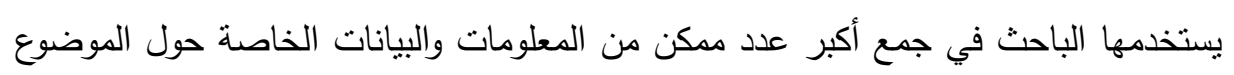

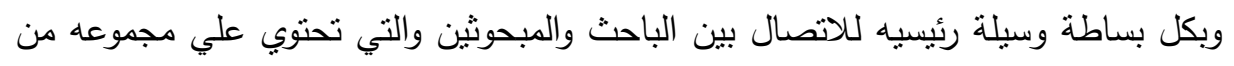
الأسئلة تخص المشكلة التي يريد الباحث معالجتها وتعرض علي عينه من الافراد ويطلب منهم الإجابة عليها كتابيا..

اشتملت الاستمارة علي (بـ)سؤال له العديد من المؤشرات الفرعية حتي يمكن التعرف

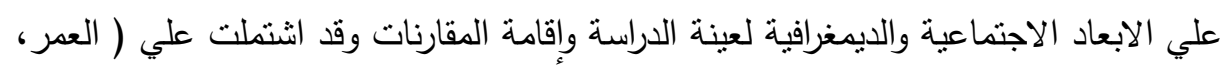

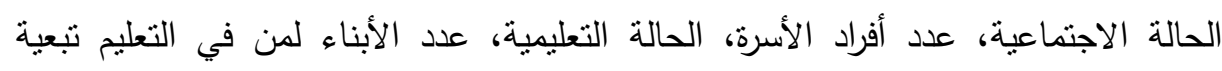

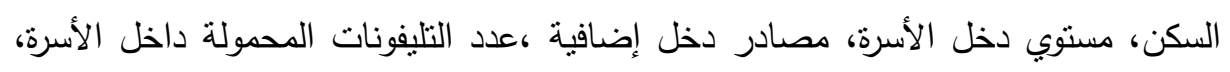
وجود الانترنت داخل المنزل).

واستخدمت الباحثة في هذه الاستمارة الصدق البنائي: يعتبر الصدق البنائي أحد مقاييس

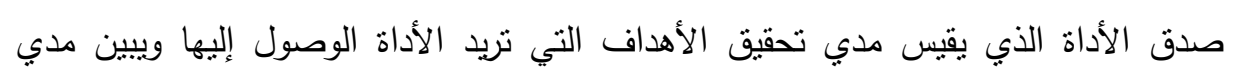
ارتباط كل محور من محاور الدراسة بالدرجة الكلية . مقياس آثز التكنولوجيا الحديثة في تحديث المجتمع البدوي (من اعداد الباحثة): يتكون المقياس من (0ب)عبارة، موزعه علي أبعاد المقياس (البعد الاول : الاسرة، البعد الثاني :الأهل ، البعد الثالث : الاصدقاء) البناء) 
صدق الاستبيان: تم استخدام الصدق البنائي: يعتبر الصدق البنائي أحد مقاييس صدق الأداة

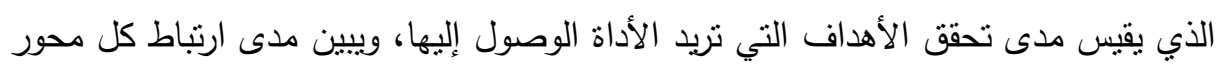
من محاور الدراسة بالدرجة الكلية لفقرات الاستبيان.

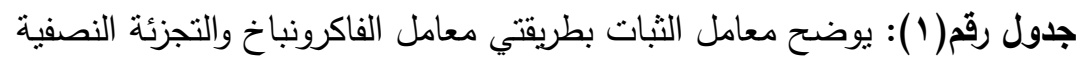

\begin{tabular}{|c|c|c|}
\hline التجزئة النصفية & معامل الفا كرونباخ & الابعاد \\
\hline$\cdot, \wedge \neg 1$ & $\cdot, V \vee$ & الاسرة \\
\hline$\cdot, V \cdot Y$ & $\cdot, 791$ & الأهل \\
\hline 710 & $\cdot, T V K$ & الأصدقاء \\
\hline$\cdot, \nabla \backslash \Gamma$ & $\cdot, \mathrm{V} O$. & الدرجة الكلية \\
\hline
\end{tabular}

جدول(ץ): يوضح معامل الارتباط بين درجة كل بعد من ابعاد الاستبيان والدرجة الكلية للاستبيان

\begin{tabular}{|c|c|c|}
\hline مستوى الدلالة & معامل بيرسون للارتباط & البعد \\
\hline \multirow{4}{*}{$\cdot, \cdot 1$} & ( & الاسرة \\
\hline &., $00 \xi$ & الأهل \\
\hline & $\cdot, 7 \leqslant \leqslant$ & الأصدقاء \\
\hline & & الدرجة الكلية \\
\hline
\end{tabular}

يبين جدول رقم (r) أن جميع معاملات الارتباط في جميع ابعاد الاستبيان دالة إحصائياً

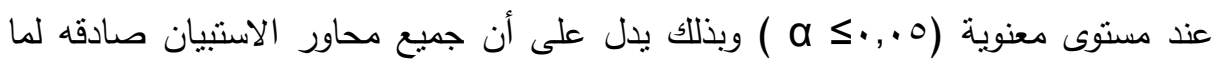

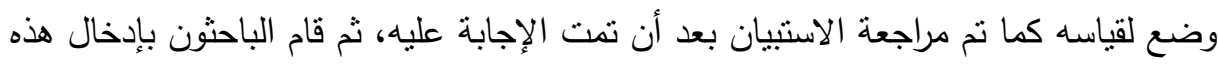

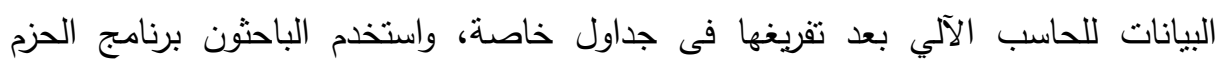
الإحصائية(SPSS) فى إجراء التحليل الإحصائي لبيانات الدراسة الميدانية. جدول(r): يظهر عدد التليفونات المحمولة لدى أفراد أسرة المبحوثين

\begin{tabular}{|c|c|c|}
\hline$\%$ & ك & الفئة \\
\hline Y 1,0 & $\varepsilon r$ & لا يوجد \\
\hline$\leqslant 0,$. & 9 . & $r-1$ \\
\hline$\overline{r q, 0}$ & or & $7-\varepsilon$ \\
\hline$\varepsilon, 0$ & 9 & $9-V$ \\
\hline$T, 0$ & 0 & من • ـ فأكثر \\
\hline$\cdots, \cdot$ & Y.. & الاجمالى \\
\hline
\end{tabular}




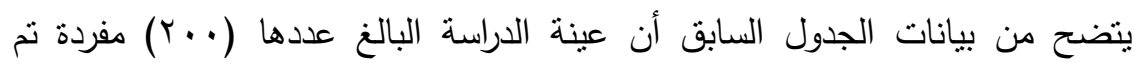

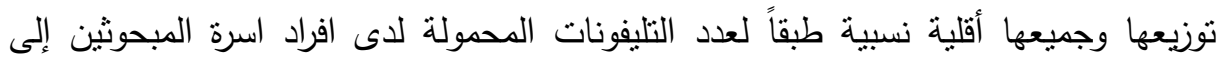

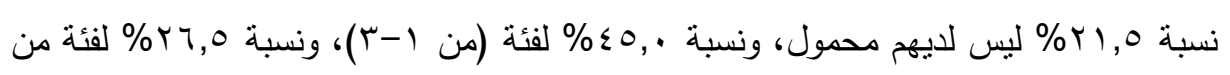
(

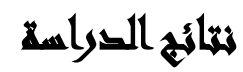

العلاقات الأسرية أكثر تأثرا بسبب استخدام وسائل التكنولوجيا الحديثة: جدول(؛): جدول يوضح وجود فرق دال احصائي عند استخدام وسائل التكنولوجيا الحديثة بين التئين

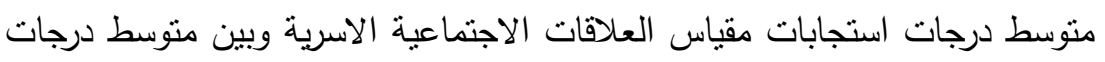

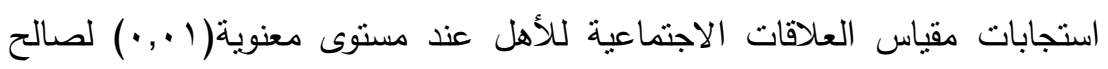

\begin{tabular}{|c|c|c|c|c|c|}
\hline & & & & ت ت ت الاسرية. & \\
\hline \multirow[b]{2}{*}{ دلالة ت } & \multirow{2}{*}{ قيمة } & \multicolumn{2}{|c|}{ مقياس العلاقّات مع الاهل } & \multicolumn{2}{|c|}{ مقياس العلافات الاسرية } \\
\hline & & الالانحرافي & المتوسط & الانحياري & المتوسط \\
\hline دالة عند ا ., . & 1,97 & $\cdot, 1 \wedge$ & $Y, \leqslant 7$ & $\cdot, 1 \wedge 9$ & $T, T Y$ \\
\hline
\end{tabular}

يتضح من بيانات الجدول السابق وجود فرق دال احصائياً بين منوسط درجات مقياس

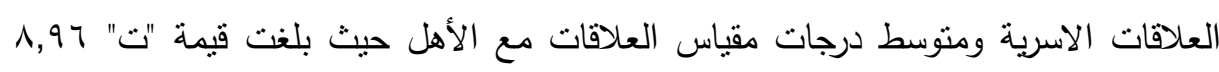

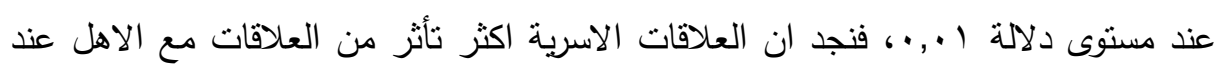

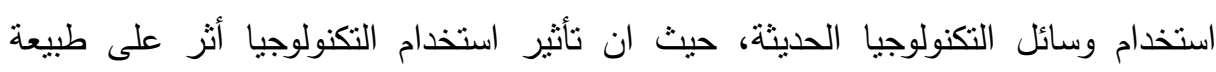

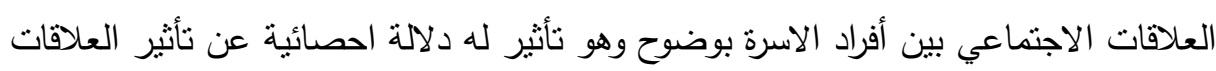
الاجتماعية للأهل.

تعقيب: إن ذللك يتمشى مع قوة وشبكة العلاقات بين أفراد الأسرة لأنها أكثر تماسكا وارتباطا

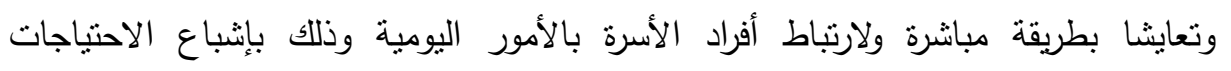

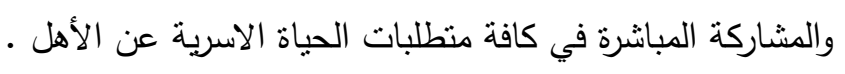

تأثر علاقات المبحوثين بالأصدقاء والأهل نتيجة استخدام التكنولوجيا الحديثة بنفس الارجة 
جدول(•): يوضح عدم وجود فروق دالة احصائية بين منوسط درجات استجابات مقياس علاقات

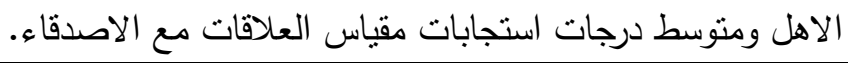

\begin{tabular}{|c|c|c|c|c|c|}
\hline \multirow[b]{2}{*}{ دلالة ت } & \multirow[b]{2}{*}{ قيمة ت } & \multicolumn{2}{|c|}{ مقياس العلاقات مع الاصدقاء } & \multicolumn{2}{|c|}{ مقياس العلافات الاهل } \\
\hline & & الانحياري & المتوسط & الالانحراف & المتوبط \\
\hline غير دالة & $1,7 \pi$ & $\cdot, \cdot \wedge$ & $r, \varepsilon r$ & $\cdot, 1 \wedge$ & $Y, \sum \uparrow$ \\
\hline
\end{tabular}

قيمة "ت" عند مستوى دلالة ه., ••: 1,97

قيمة "ت" عند مستوى دلالة ا., Y.,

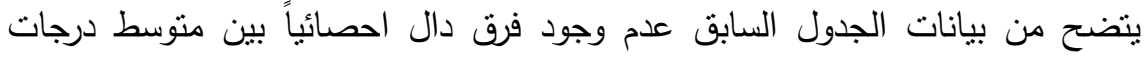

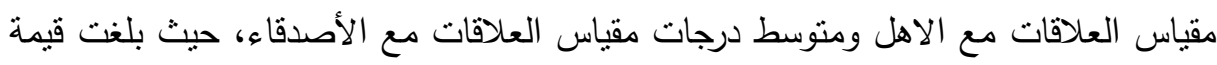

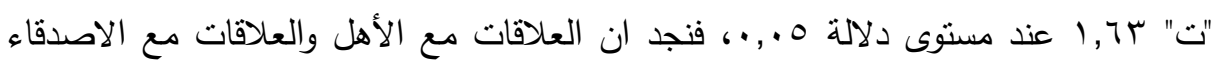

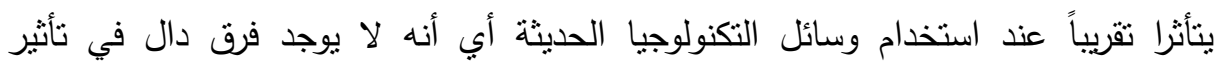
استخدام التكنولوجيا في العلاقات سواء مع الاهل أو الاصدقاء أو مع الجيران أى أنه نفس التس

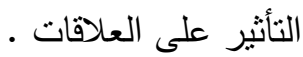
تعقيب: أن علاقات المبحوثين مع الأهل بعيدا عن الأسرة الصغيرة التى يعيشون فيها أو

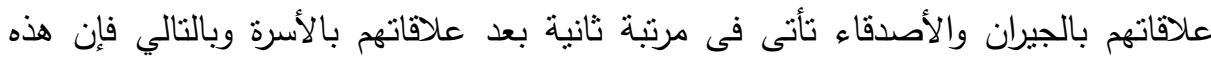

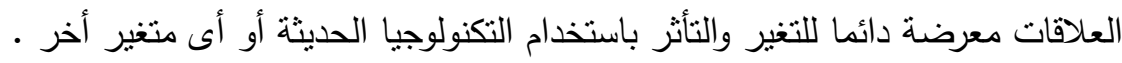


تمسك رجال البدو بالزى التقليدى رغم استخدام وسائل التكنولوجيا الحديثة جدول(7): يوضح عدم وجود فرق دال احصائي بين متوسط درجات استجابات انتشار استخدام

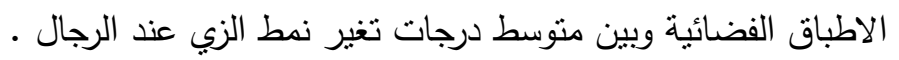

\begin{tabular}{|c|c|c|c|c|c|c|c|}
\hline \multirow{2}{*}{ دلالة كاr } & \multirow{2}{*}{ كاr } & \multirow{2}{*}{ الاجمالي } & \multicolumn{2}{|c|}{ استخدام الاطباق الفضائية } & & & \\
\hline & & & نعم & احيانا & & & \\
\hline \multirow{8}{*}{ غير دالة } & \multirow{8}{*}{$\cdot, V \leqslant V$} & or & or & 1 & العدد & & \multirow{6}{*}{ تغير نمط للرجال } \\
\hline & & YY,O & $r 7, r$ & $0 \cdot, \cdot$ & $\%$ & سعم & \\
\hline & & $1 \leq 0$ & $1 \leq \varepsilon$ & 1 & العدد & \multirow{2}{*}{ 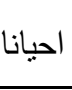 } & \\
\hline & & $V Y, 0$ & $V Y, V$ & $0 \cdot, \cdot$ & $\%$ & & \\
\hline & & $r$ & $r$ & $\cdot$ & العدد & \multirow{2}{*}{$y$} & \\
\hline & & $1, \cdot$ & $1, \cdot$ & $\cdot, \cdot$ & $\%$ & & \\
\hline & & $r \ldots$ & 191 & r & العدد - العد & \multirow{2}{*}{\multicolumn{2}{|c|}{ الاجمالي }} \\
\hline & & $1 \cdots, \cdot$ & $1 \cdots$, & $1 \cdots, \cdot$ & $\%$ & & \\
\hline
\end{tabular}

يتضح من بيانات الجدول السابق عدم وجود علاقة ارتباطية دالة احصائياً بين انتشار

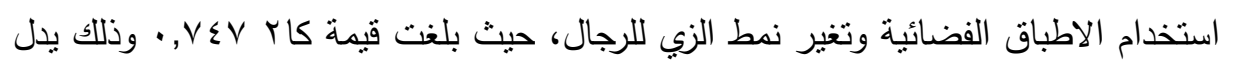

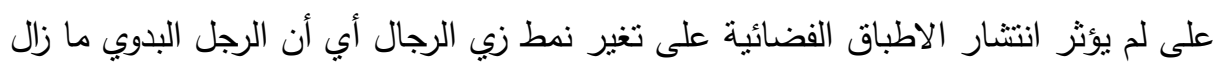

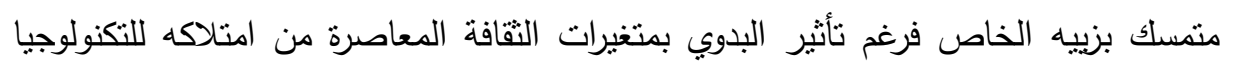

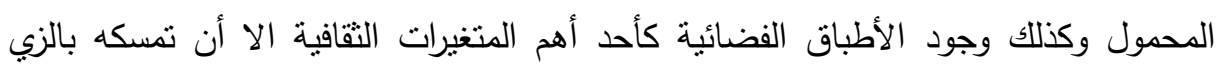

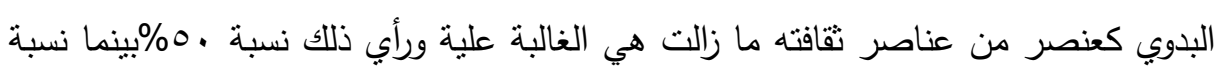

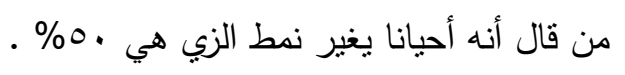

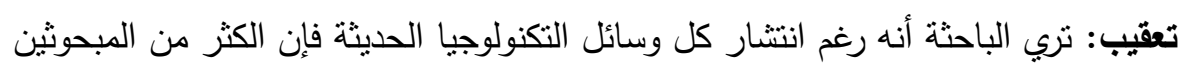

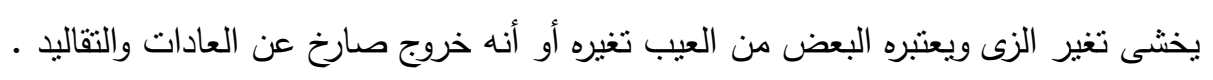




\section{النحوسيامت}

ا ـ التوعية بدور المنظمات الرسمية وغيرها من المواطنين في محاربة ثقافة العيب .

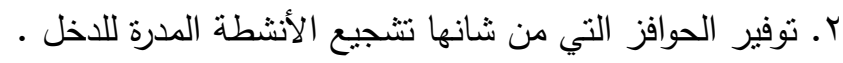

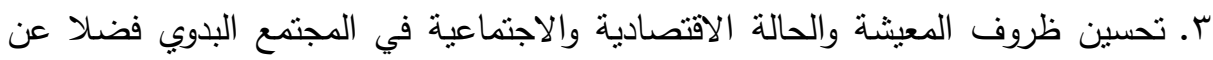

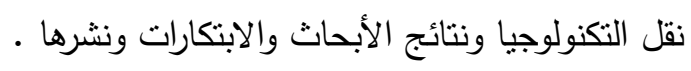

ع. عمل ندوات وورش عمل بهدف التوعية لمجتمع البدو بايجابيات وسلبيات التكنولوجيا الحديثة .

ه. توسيع نطاق مشاركة البدو من خلال دعم المبادرات الثبابية وعقد الندوات والمؤتمرات

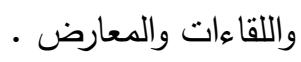

7. تكثيف الحملات الإعلامية التي توح طرق استخدام التكنولوجيا الحديثة .

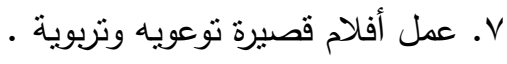

^. نظوير أساليب المشاركة الإيجابية للشباب من خلال نشر ثقافة استخدام وسائل التكنولوجيا

$$
\text { والحديثة في قضايا المجنمع }
$$

9 9. عمل برامج توعية لنتظيم الأسرة .

• . إعداد أبحاث ودراسات عن قضايا المجتمع البدوي واحتياجاتهم ووضع سياسات

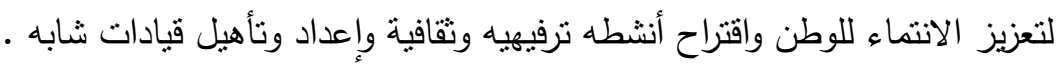

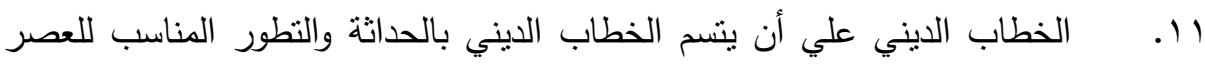

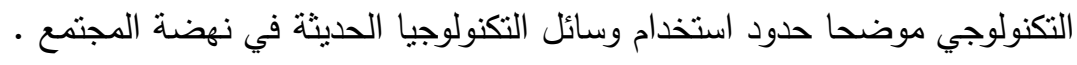

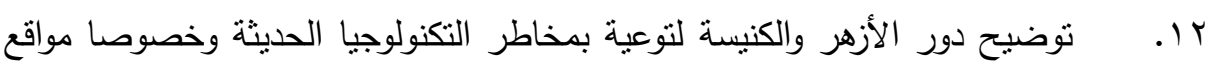

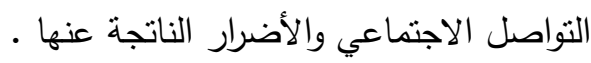




\section{المرائية}

$$
\begin{aligned}
& \text { أحمد عويدى العبادى( ع \9 ()): المرأة البدوية، وزارة الاعلام، عمان }
\end{aligned}
$$

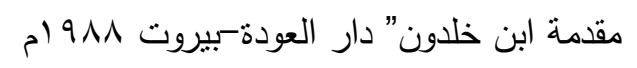

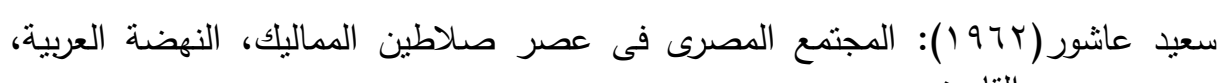

$$
\begin{aligned}
& \text { القاهرة }
\end{aligned}
$$

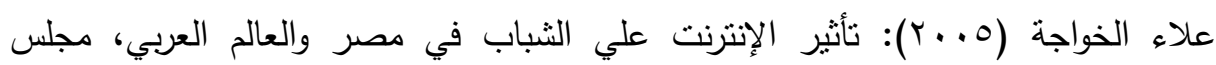

$$
\begin{aligned}
& \text { الوزراء، مركز المعلومات ودعم اتخاذ القرار ، القاهرة، نوفمبر }
\end{aligned}
$$

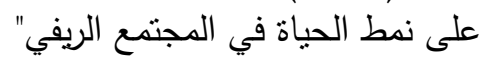

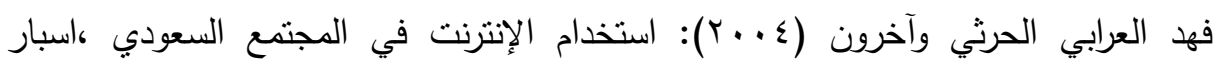

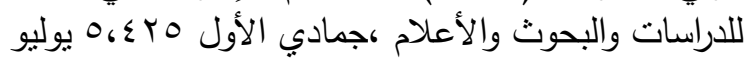

$$
\begin{aligned}
& \text { مذكرات شاهد للقرن" مالك بن نبي دار الفكر الطبعة الثانية ؟ .. بام }
\end{aligned}
$$

Garuitz, Madelaine- Methodes des seiencessariales Eoldalloz ,paris ,1988

O.N.S. collection des statistique N: 88. 1998. p12

M.Iutoud:tableaugenerddescommumes de

I'algerie

Constantinerendeimpremerie 1911 
مجلة العلوم البيئية

معهد الدراسات والبحوث البيئية - جامعة عين شمس لينان

\title{
MODERN TECHNOLOGY AND ITS EFFECT ON MODERNIZING BEDOUIN COMMUNITIES FIELD STUDY IN MARSA MATROUH
}

Aya Sh. Mohsen ${ }^{(1)}$;Fatma Al-Kalin ${ }^{(2)}$ and Mervat Shamroukh ${ }^{(3)}$

1) General Union of Egyptian Workers, Ministry of Manpower.

2). Girls College, Ain Shams University 3) Institute of Social Work, Cairo.

\begin{abstract}
This study aims to identify the variables resulting from the use of modern communication technology and its effect in modernizing the Bedouin community. The researcher used the descriptive approach and blogging because it is the closest approach to achieving the research objectives.

The study was descriptive and the data were collected using some anthropological methods, a personal interview tool and questionnaire.

This study aims to identify the variables resulting from the use of modern communication technology and its effect in modernizing the Bedouin community. The researcher used the descriptive approach and blogging because it is the closest approach to achieving the research objectives.

The study was descriptive and the data were collected using some anthropological methods, a personal interview tool and questionnaire.

The researchers used the theory of functional constructivism and the theory of "Daniel Lerner" and some other theories of modern sociology that explain the impact of modern modern technology on the pattern of relationships and these are the most appropriate approaches to the present study as the use of modern technology that carries many of the programs employed by man in his service, including communication programs It is one of the most important means of mass
\end{abstract}

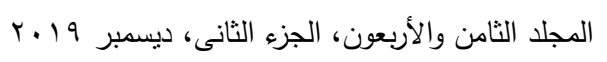


communication that allows individuals, communities, minorities and the majority to express their views and support it in all ways of expression and thus affect the nature of social relations and also allow the transfer and exchange Knowledge of different cultures.

The study resulted in a set of results including:

- Most of the $79.5 \%$ of the Bedouin have mobile phones and a social media account and spend a lot of time using the Internet

- The most important changes associated with the use of modern technology is the nature of social relations

- One of the most important variables resulting from the use of modern technology is the waste of time and weak social relations.

- The results also indicate the presence of $79 \%$ of the holders of telephone and computer users in the Badia community and follow-up multiple television programs and this is evident in uniform for both men and women and some of the phrases used to keep them away from their culture.

The study concluded with a number of recommendations including: Using modern technology and staying away from the programs that promoted the cultures of the West that are incompatible with Eastern Arab customs and traditions

Raising awareness of the importance of using modern technology especially social networking sites and the damages that can occur 